ARTICLE

https://doi.org/10.1038/s41467-018-07693-x

\title{
Deoxyribose and deoxysugar derivatives from photoprocessed astrophysical ice analogues and comparison to meteorites
}

\author{
Michel Nuevo (iD ${ }^{1,2}$, George Cooper ${ }^{3} \&$ Scott A. Sandford (iD ${ }^{1}$
}

\begin{abstract}
Sugars and their derivatives are essential to all terrestrial life. Their presence in meteorites, together with amino acids, nucleobases, amphiphiles, and other compounds of biological importance, may have contributed to the inventory of organics that played a role in the emergence of life on Earth. Sugars, including ribose (the sugar of RNA), and other sugar derivatives have been identified in laboratory experiments simulating photoprocessing of ices under astrophysical conditions. In this work, we report the detection of 2-deoxyribose (the sugar of DNA) and several deoxysugar derivatives in residues produced from the ultraviolet irradiation of ice mixtures consisting of $\mathrm{H}_{2} \mathrm{O}$ and $\mathrm{CH}_{3} \mathrm{OH}$. The detection of deoxysugar derivatives adds to the inventory of compounds of biological interest that can form under astrophysical conditions and puts constraints on their abiotic formation pathway. Finally, we report that some of the deoxysugar derivatives found in our residues are also newly identified in carbonaceous meteorites.
\end{abstract}

\footnotetext{
${ }^{1}$ NASA Ames Research Center, MS 245-6, Moffett Field, CA 94035, USA. ${ }^{2}$ BAER Institute, NASA Research Park, MS 18-4, Moffett Field, CA 94035, USA.

${ }^{3}$ NASA Ames Research Center, MS 239-4, Moffett Field, CA 94035, USA. Correspondence and requests for materials should be addressed to

M.N. (email: michel.nuevo-1@nasa.gov)
} 
S ugars (monosaccharides) and their derivatives are ubiquitous in nature and essential to biological processes in all terrestrial life. Sugars themselves play several roles in biology. For example, they are used as structural backbones in RNA (ribose) and DNA (deoxyribose), as well as cell walls in plants (cellulose). They also serve as energy sources (glucose) or energy storage (glycogen and starch) $)^{1,2}$. Structurally, sugars are carbohydrates of general formula $\mathrm{C}_{n} \mathrm{H}_{2 n} \mathrm{O}_{n}$, and the simplest sugars are defined as aldehydes (aldoses) or ketones (ketoses) containing at least two hydroxyl groups ${ }^{3}$. Sugar derivatives, collectively referred to as polyols, include sugar alcohols and sugar acids. In the case of aldoses, such sugar alcohols and acids are sugars in which the terminal aldehyde group is replaced by a primary alcohol or a carboxylic acid group, respectively. Deoxy variants of sugars, sugar alcohols, and sugar acids, are sugar derivatives that are lacking one or more hydroxyl groups with respect to their corresponding parent compounds (e.g., deoxyribose vs. ribose).

The smallest ketose sugar, dihydroxyacetone, as well as several sugar acids and sugar alcohols-with up to 6 carbon atoms-have been detected in several carbonaceous chondrites including Murchison and Murray, and shown to be extraterrestrial in ori$\operatorname{gin}^{4,5}$. The presence of sugar derivatives in primitive meteorites, together with other compounds of biological interest such as amino acids ${ }^{6,7}$, nucleobases ${ }^{8,9}$, and amphiphiles ${ }^{10,11}$ is consistent with a scenario in which a significant fraction of the inventory of compounds from which biological processes started on the primitive Earth may have been delivered via comets, meteorites, and interplanetary dust particles (IDPs) ${ }^{12,13}$.

Over the last 25 years, laboratory experiments simulating the photo-irradiation or particle bombardment of mixtures of astrophysical ice analogs at low temperatures (10-80 K) have shown that organic compounds can form under astrophysical, non-biological conditions. In particular, the ultraviolet (UV) irradiation of ice mixtures consisting of $\mathrm{H}_{2} \mathrm{O}, \mathrm{CH}_{3} \mathrm{OH}, \mathrm{CO}, \mathrm{CO}_{2}$, $\mathrm{CH}_{4}$, and/or $\mathrm{NH}_{3}$ leads to the formation of compounds of astrobiological interest such as amino acids ${ }^{14-16}$, nucleobases ${ }^{17,18}$, functionalized polycyclic aromatic hydrocarbons (PAHs) ${ }^{19,20}$, amphiphiles ${ }^{21}$, as well as urea, hydantoin, and small aldehydes ${ }^{22-}$ 24. A variety of organic compounds have also been shown to form at $5 \mathrm{~K}$ when ice mixtures containing $\mathrm{CH}_{3} \mathrm{OH}$ were UV irradiated or bombarded with energetic electrons ${ }^{25,26}$. Finally, a large variety of sugar alcohols, sugars (including ribose, the sugar of RNA), and sugar acids with up to 5 carbon atoms have been identified in residues produced from the UV irradiation of ice mixtures containing $\mathrm{H}_{2} \mathrm{O}$ and $\mathrm{CH}_{3} \mathrm{OH}$ at low temperatures ${ }^{27,28}$. In contrast, only 1,3-propanediol (3C deoxysugar alcohol) was unambiguously identified in a laboratory residue 28 , while several deoxysugar acids have been found in meteorites ${ }^{4,5}$. The previous non-detection of deoxysugar derivatives in laboratory residues led to the conclusion that in such photo-irradiation experiments, sugar derivatives were formed via a formose-type reaction pathway $^{28}$.

The present study is based on the analysis of 5 independent residues produced from the $\mathrm{UV}$ irradiation of $\mathrm{H}_{2} \mathrm{O}: \mathrm{CH}_{3} \mathrm{OH}$ and $\mathrm{H}_{2} \mathrm{O}:{ }^{13} \mathrm{CH}_{3} \mathrm{OH}$ ice mixtures in relative proportions of $2: 1$ at $12 \mathrm{~K}$. The results obtained for these 5 residues are consistent with 12 other residues produced from $\mathrm{H}_{2} \mathrm{O}: \mathrm{CH}_{3} \mathrm{OH}$ ice mixtures in relative proportions $2: 1$ and 5:1 that were originally analyzed for the presence of other sugar derivatives. The 2:1 ratio between $\mathrm{H}_{2} \mathrm{O}$ and $\mathrm{CH}_{3} \mathrm{OH}$ ices corresponds to the upper limit of the $\left[\mathrm{H}_{2} \mathrm{O}\right] /\left[\mathrm{CH}_{3} \mathrm{OH}\right]$ ratio observed in cold interstellar clouds ${ }^{29,30}$. In two of the 5 experiments prepared for the present study, methanol was isotopically labeled with ${ }^{13} \mathrm{C}$ in order to verify that the compounds detected in the residues were not due to contamination. All residues were analyzed with gas chromatography coupled with mass spectrometry (GC-MS) using three distinct derivatization methods and temperature programs (see Methods). Most compounds were identified via their $(+)$-butyl/ trifluoroacetyl (but/TFA) derivatives by comparison with commercial standards prepared in the same manner as the samples, while some were identified via their tert-butyldimethylsilyl $(t$ BDMS) and/or trimethylsilyl (TMS) derivatives (see Methods). GC-MS analysis of residues with the (+)-butanol/TFAA method allowed for the enantiomeric separation of most of the sugar derivatives, thus allowing for an additional assessment of possible contamination in the samples.

\section{Results}

Identification of deoxyribose and deoxysugar derivatives. All the residues produced in this work contained a wide variety of sugars, sugar alcohols, and sugar acids, with a similar distribution to previous laboratory ice UV irradiation studies ${ }^{27,28}$. In addition to these common sugar derivatives, we identified a number of deoxysugars, deoxysugar alcohols, and deoxysugar acids, i.e., compounds in which one or more carbon atoms is not bonded to a hydroxyl $(\mathrm{OH})$ group relative to the corresponding canonical parent sugars, sugar alcohols, and sugar acids, respectively. These include the 5-carbon (5C) deoxysugar 2-deoxyribose $\left(\mathrm{C}_{5} \mathrm{H}_{10} \mathrm{O}_{4}\right)$ (the structural backbone of DNA), as well as the $3 \mathrm{C}$ and $4 \mathrm{C}$ deoxysugar alcohols 1,2-propanediol $\left(\mathrm{C}_{3} \mathrm{H}_{8} \mathrm{O}_{2}\right)$, 1,3-propanediol $\left(\mathrm{C}_{3} \mathrm{H}_{8} \mathrm{O}_{2}\right)$, 2-methyl-1,3-propanediol $\left(\mathrm{C}_{4} \mathrm{H}_{10} \mathrm{O}_{2}\right), 1,2,3$-butanetriol $\left(\mathrm{C}_{4} \mathrm{H}_{10} \mathrm{O}_{3}\right)$, and 1,2,4-butanetriol $\left(\mathrm{C}_{4} \mathrm{H}_{10} \mathrm{O}_{3}\right)$. The molecular structures of all the compounds identified in our residues are shown in Supplementary Fig. 1. This is the first definitive identification of a deoxysugar in laboratory ice photolysis residues. Only one other deoxysugar derivative, namely, 1,3-propanediol (deoxysugar alcohol, also present in our residues) was unambiguously detected in one other laboratory residue in a previous study, together with tentative identifications of 2-methylglycerol (deoxysugar alcohol) and 2-methylglyceric acid (deoxysugar acid) (not detected in our residues) $^{28}$.

The GC-MS chromatograms and mass spectra supporting the identification of 2-deoxyribose and several deoxysugar alcohols in our residues, produced from the UV irradiation of $\mathrm{H}_{2} \mathrm{O}: \mathrm{CH}_{3} \mathrm{OH}$ (2:1) and $\mathrm{H}_{2} \mathrm{O}:{ }^{13} \mathrm{CH}_{3} \mathrm{OH}(2: 1)$ ice mixtures, are shown in Fig. 1 (deoxyribose), Fig. 2 (4C deoxysugar alcohols), and Supplementary Fig. 2 (3C deoxysugar alcohols). The peaks eluting at retention times around 57.0 and $57.3 \mathrm{~min}$ in Fig. 1a are tentatively assigned to the $\mathrm{D}$ and $\mathrm{L}$ enantiomers of 2-deoxyxylose, respectively. This tentative identification is based on the mass spectra of these peaks (Supplementary Fig. 3), which are very similar to that of 2-deoxyribose (Fig. 1b), and because 2deoxyxylose is the only possible diastereomer of 2-deoxyribose. Although its identification is not formally confirmed yet for lack of a standard, the mass spectra of diastereomers of polyols are usually identical with the derivatization methods used in the present work.

Typical residues were produced from $\mathrm{H}_{2} \mathrm{O}: \mathrm{CH}_{3} \mathrm{OH}(2: 1)$ and $\mathrm{H}_{2} \mathrm{O}^{13}{ }^{13} \mathrm{CH}_{3} \mathrm{OH}(2: 1)$ ice mixtures in which totals of $1.23 \mathrm{mmol}$ of $\mathrm{H}_{2} \mathrm{O}$ and $0.61 \mathrm{mmol}$ of $\mathrm{CH}_{3} \mathrm{OH} /{ }^{13} \mathrm{CH}_{3} \mathrm{OH}$ were co-deposited at

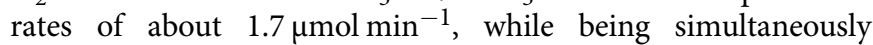
irradiated for $17-19 \mathrm{~h}$ with photon doses of $0.35-0.39$ photons molecule $^{-1}$. The deoxysugar derivatives, as well as ribose for comparison, identified in all regular (i.e., mostly ${ }^{12} \mathrm{C}$ ) and ${ }^{13} \mathrm{C}$ labeled residues are summarized in Table 1 . Note that the abundances given for 1,2-propanediol and 1,3-propanediol are lower limits, because these compounds are very volatile and a 

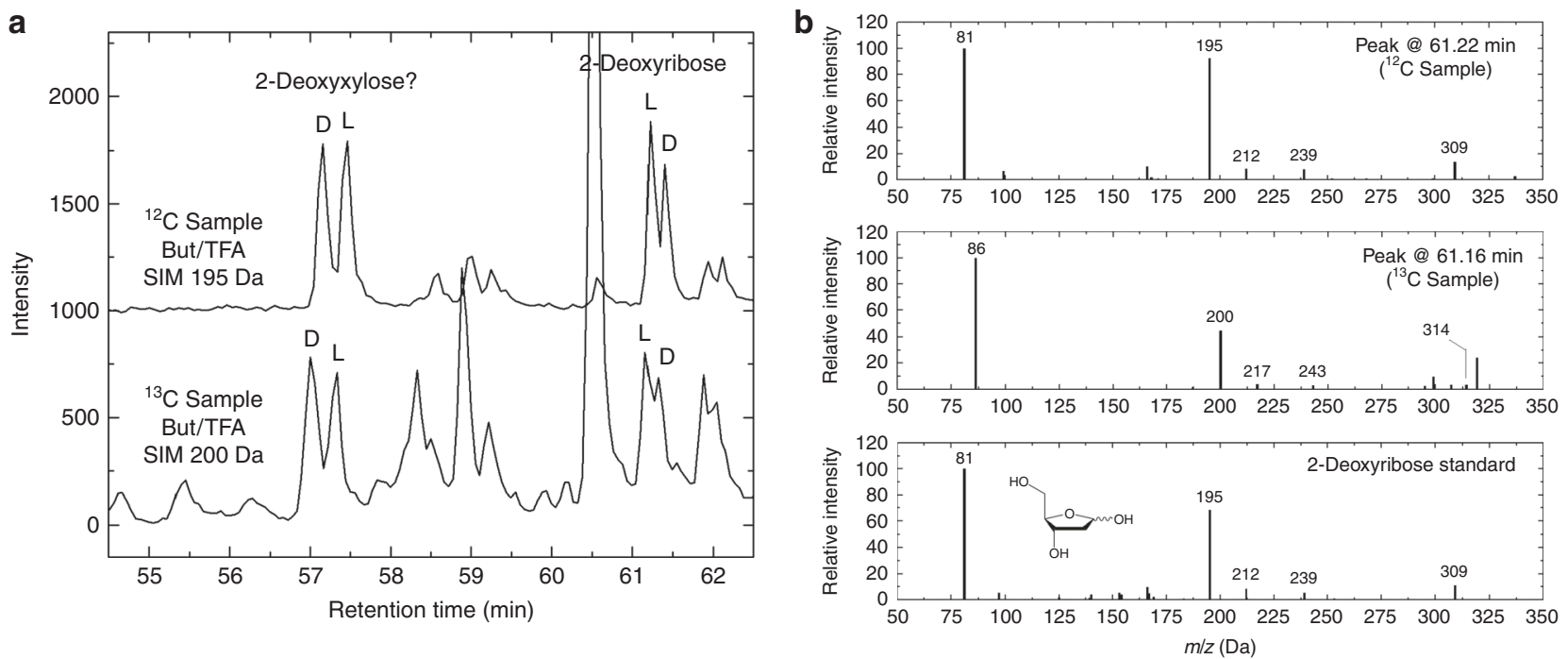

Fig. 1 Identification of 2-deoxyribose in ice photolysis residues. a Single-ion monitoring (SIM) chromatograms of residues produced from the UV irradiation of $\mathrm{H}_{2} \mathrm{O}: \mathrm{CH}_{3} \mathrm{OH}(2: 1)\left({ }^{12} \mathrm{C}\right.$ sample, $\left.\mathrm{m} / \mathrm{z}=195 \mathrm{Da}\right)$ and $\mathrm{H}_{2} \mathrm{O}:{ }^{13} \mathrm{CH}_{3} \mathrm{OH}(2: 1)\left({ }^{13} \mathrm{C}\right.$ sample, $\left.200 \mathrm{Da}\right)$ ice mixtures after derivatization with (+)-2-butanol/TFAA. The peaks around 57.0 and $57.3 \mathrm{~min}$ in both chromatograms are tentatively assigned to 2-deoxyxylose (see Supplementary Fig. 2). Intensities are offset for clarity. b From top to bottom, mass spectra of the peaks assigned to 2-deoxy-L-ribose in the regular residue, the ${ }^{13} \mathrm{C}$-labeled residue, and a standard of 2 deoxyribose. The molecular structure of 2-deoxyribose is shown without derivatization. Assignments of the fragments in the mass spectra can be found in Supplementary Table 1

non-negligible fraction of them may have sublimed away during the ice warm-up phase and/or the preparation of the samples for GC-MS analysis (see Methods). In the residue whose chromatogram is shown as the bottom trace of Fig. 1a, the abundances of 2deoxyribose $\left({ }^{13} \mathrm{C}\right.$-labeled $\mathrm{D}+\mathrm{L}$ enantiomers $)$ ranged from 334 to $3855 \mathrm{pmol}$, which corresponds to production yields of $3 \times 10^{-6}$ to $3.2 \times 10^{-5}$ from the starting ${ }^{13} \mathrm{C}$-methanol.

Residues produced in these experiments probably contain several other deoxysugar derivatives, as supported by the presence of several peaks in the GC-MS chromatograms that display fragments with masses consistent with such compounds. These include an unidentified $4 \mathrm{C}$ deoxysugar acid that was tentatively assigned to 3,4-dihydroxybutyric acid by comparison of the mass spectrum of its $t$-BDMS derivative in the samples with the NIST database (Supplementary Fig. 4). However, their formal identification was difficult to assure because the corresponding standards were unavailable (only some of the isomers of the $4 \mathrm{C}$ deoxysugar acids were available as standards; see Methods), and because their high retention times may indicate that they are present as dimers or higher oligomers rather than monomers. The assignment to a deoxysugar acid is based on the presence in its mass spectrum of the fragment ion at $267 \mathrm{Da}\left(270 \mathrm{Da}\right.$ for ${ }^{13} \mathrm{C}$ labeled compounds; Supplementary Fig. 4), which is due to the loss of a carboxyl/butyl group. In addition, the 6C deoxysugars 2deoxygalactose and 2-deoxyglucose were searched for in the same residues, but the low signal-to-noise for the corresponding peaks could neither confirm nor disprove their presence in the residues.

Sugar derivatives are also known to form in detectable amounts in residues produced from the $\mathrm{UV}$ irradiation of simple ice mixtures containing $\mathrm{H}_{2} \mathrm{O}$ and $\mathrm{CH}_{3} \mathrm{OH}$ at low temperature ${ }^{27,28}$. In the five residues that were analyzed in the present study, we also detected several sugar alcohols, sugars, and sugar acids (in decreasing order of abundances), including ribose (racemic) (Fig. 3) with abundances of $237-2467 \mathrm{pmol}\left(920 \mathrm{pmol}\right.$ in the ${ }^{13} \mathrm{C}$ labeled residue shown in Fig. 1) (Table 1).
Production of indigenous compounds vs. contamination. The 2-deoxyribose and most of the other deoxysugar derivatives identified in the residues produced from ices containing ${ }^{13} \mathrm{C}$ methanol were found to be isotopically labeled with ${ }^{13} \mathrm{C}$, as shown in their mass spectra (Figs. 1 and 2). The only exception comes from 1,2-propanediol and 1,3-propanediol, which could not be found in ${ }^{13} \mathrm{C}$-labeled residues (Supplementary Fig. 2), probably because of their high volatility and the fact that abundances in these ${ }^{13} \mathrm{C}$-labeled residues were lower than in regular $\left({ }^{12} \mathrm{C}\right)$ residues.

The peaks assigned to the enantiomers of 2-deoxyribose (Fig. 1) and those tentatively assigned to those of 2-deoxyxylose (Supplementary Fig. 3) show that these compounds were formed in racemic mixtures in both regular and ${ }^{13} \mathrm{C}$-labeled residues. This indicates that the compounds identified in our residues result from the UV photoprocessing of the ices, and rules out the possibility of exogenous contamination. Indeed, not only is 2deoxy-L-ribose a very rare compound on Earth as biological DNA exclusively uses the $\mathrm{D}$ enantiomer, but biological processes also tend to enrich biomolecules in ${ }^{12} \mathrm{C}$.

The GC-MS chromatograms of three independent control samples, one in which no ice was deposited and the substrate irradiated, one in which only $\mathrm{H}_{2} \mathrm{O}$ was deposited and irradiated, and one in which an $\mathrm{H}_{2} \mathrm{O}:{ }^{13} \mathrm{CH}_{3} \mathrm{OH}(2: 1)$ ice mixture was deposited but not irradiated (Supplementary Fig. 5 and Methods), show small amounts of contaminant ${ }^{12} \mathrm{C}$-2-deoxy-D-ribose (Supplementary Fig. 5a), but no contaminant ${ }^{12} \mathrm{C}$-ribose. DArabinose, which elutes right after D-ribose (Supplementary Fig. 5b), is produced in our experiments and found to be present in all residues. The level of contamination from ${ }^{12} \mathrm{C}$-2-deoxy-Dribose varies slightly from one control sample to another, with an estimated contribution smaller than $9 \%$ of the amounts of 2 deoxyribose measured in the residues. This suggests that such contamination may come from the solvents, derivatization agents, and/or glassware. The contribution of contaminant 2-deoxyribose 
a

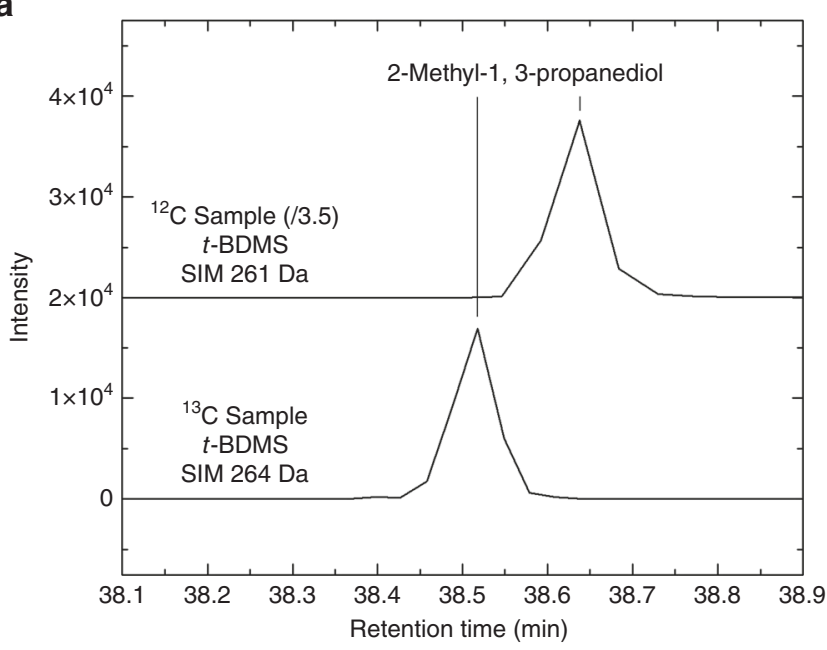

C

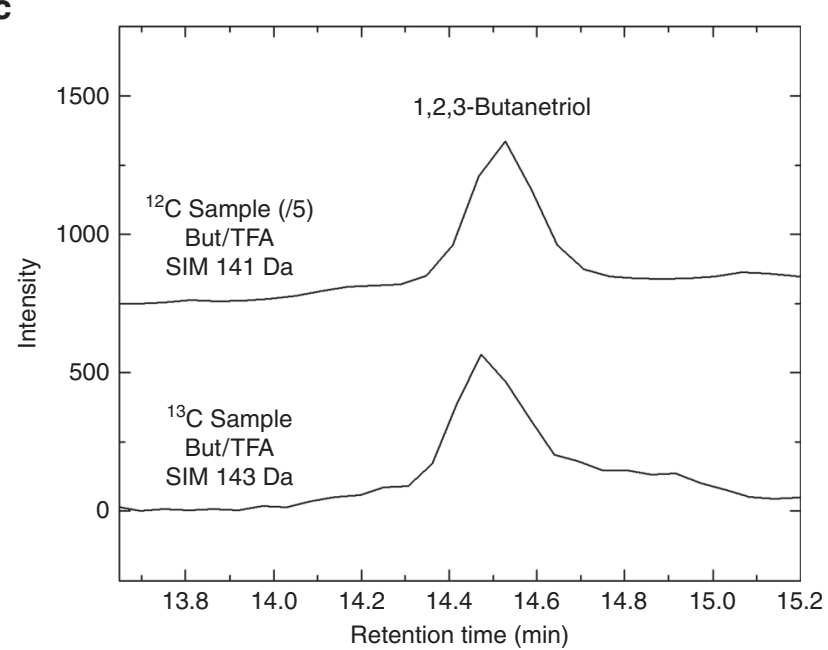

e

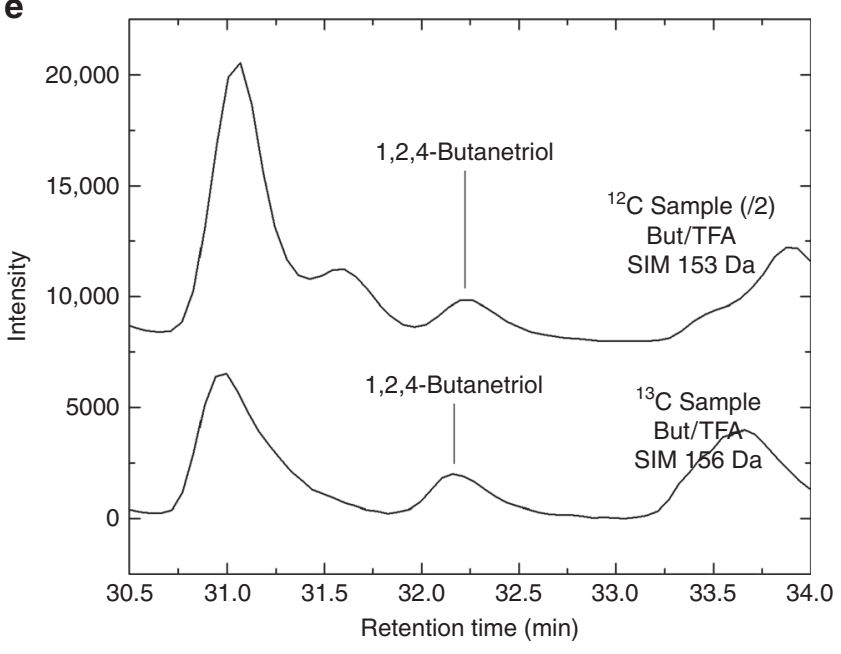

was taken into account for the produced abundances in the residues (Tables 1 and 2).

\section{Discussion}

The formation mechanisms for deoxysugar derivatives under our experimental conditions simulating ice photochemistry in cold
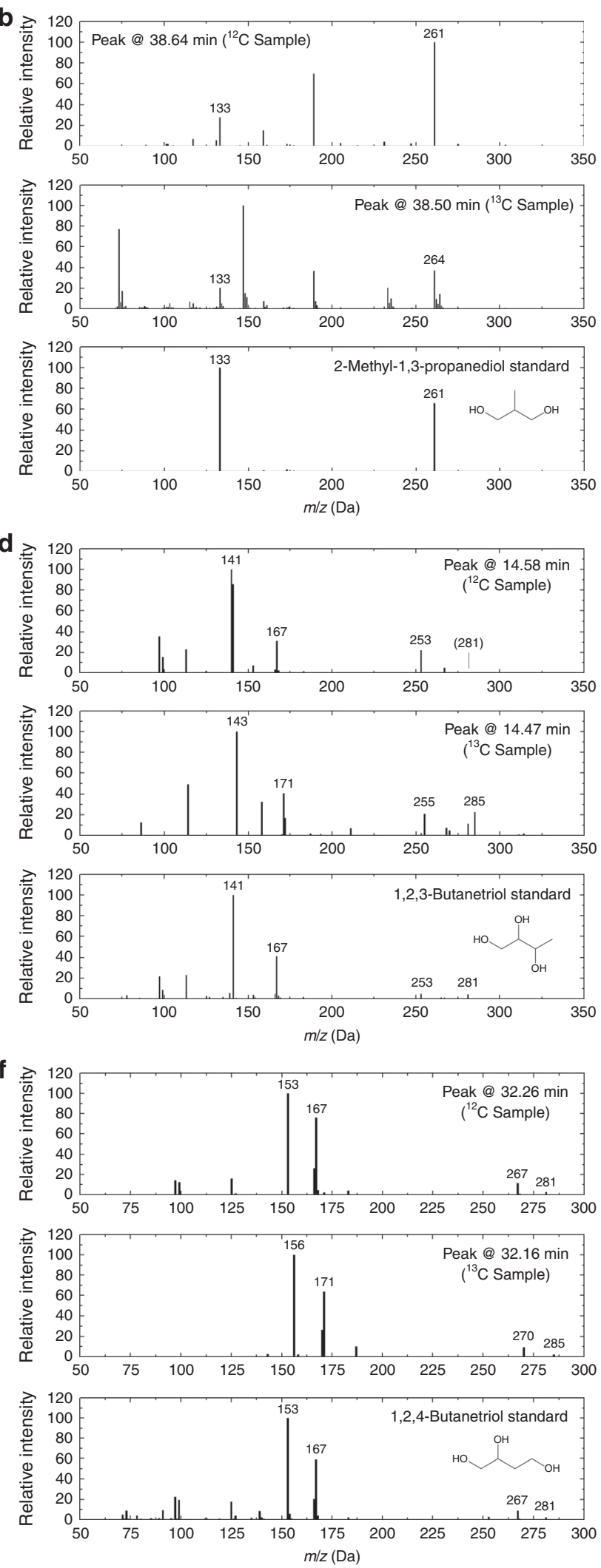

astrophysical environments are difficult to determine, due to the stochastic nature of the chemical processes taking place in the ice matrix. Indeed, the energy of the incident UV photons is sufficient to break chemical bonds and ionize species, resulting in the release of $\mathrm{H}$ atoms together with $\mathrm{OH}, \mathrm{CH}_{3}, \mathrm{CH}_{2} \mathrm{OH}$, and $\mathrm{CH}_{3} \mathrm{O}$ radicals and ions from the photolysis of $\mathrm{H}_{2} \mathrm{O}$ and $\mathrm{CH}_{3} \mathrm{OH}$. At 12 
Fig. 2 Identification of the $4 \mathrm{C}$ deoxysugar alcohols 2-methyl-1,3-propanediol, 1,2,3-butanetriol, and 1,2,4-butanetriol in ice photolysis residues. a SIM chromatograms of residues produced from the UV irradiation of $\mathrm{H}_{2} \mathrm{O}: \mathrm{CH}_{3} \mathrm{OH}(2: 1)\left({ }^{12} \mathrm{C}\right.$ sample, $\left.\mathrm{m} / \mathrm{z}=261 \mathrm{Da}\right)$ and $\mathrm{H}_{2} \mathrm{O}:{ }^{13} \mathrm{CH}_{3} \mathrm{OH}(2: 1)\left({ }^{13} \mathrm{C}\right.$ sample, 264 $\mathrm{Da}$ ) ice mixtures after derivatization with MTBSTFA. Intensities are offset for clarity. b From top to bottom, mass spectra of the peaks assigned to 2methyl-1,3-propanediol in the regular residue, the ${ }^{13} \mathrm{C}$-labeled residue, and a standard of 2-methyl-1,3-propanediol. The difference in relative intensities for the peaks at 133 and $261 \mathrm{Da}$ suggests a coelution with an unidentified compound with similar mass fragments. c SIM chromatograms of the same regular $(141 \mathrm{Da})$ and ${ }^{13} \mathrm{C}$-labeled $(143 \mathrm{Da})$ residues after derivatization with $(+)$-2-butanol/TFAA. Intensities are offset for clarity. $\mathbf{d}$ From top to bottom, mass spectra of the peaks assigned to 1,2,3-butanetriol in the regular residue, the ${ }^{13} \mathrm{C}$-labeled residue, and a standard of 1,2,3-butanetriol. e SIM chromatograms of the same regular $(153 \mathrm{Da})$ and ${ }^{13} \mathrm{C}$-labeled $(156 \mathrm{Da})$ residues after derivatization with $(+)$-2-butanol/TFAA. Intensities are offset for clarity. $\mathbf{f}$ From top to bottom, mass spectra of the peaks assigned to 1,2,4-butanetriol in the regular residue, the ${ }^{13} \mathrm{C}$-labeled residue, and a standard of 1,2,4-butanetriol. Molecular structures are shown without derivatization. Assignments of the fragments in the mass spectra can be found in Supplementary Table 1

\section{Table 1 Deoxysugar derivatives identified in the ice photolysis residues (regular and ${ }^{13} \mathrm{C}$-labeled)}

\begin{tabular}{|c|c|c|c|c|}
\hline \multicolumn{5}{|l|}{ Deoxysugars } \\
\hline 2-Deoxyribose & $\mathrm{C}_{5} \mathrm{H}_{10} \mathrm{O}_{4}$ & $61.2,61.4$ & $217-3855$ & Undeterminedk \\
\hline \multicolumn{5}{|l|}{ Deoxysugar alcohols } \\
\hline 1,2-Propanediolf & $\mathrm{C}_{3} \mathrm{H}_{8} \mathrm{O}_{2}$ & 9.9 & $\geq 8-375$ & $Y_{e s^{l, m}}$ \\
\hline 1,3-Propanediolf,g & $\mathrm{C}_{3} \mathrm{H}_{8} \mathrm{O}_{2}$ & 36.9 & $\geq 19-27$ & No \\
\hline 1,2,3-Butanetriol & $\mathrm{C}_{4} \mathrm{H}_{10} \mathrm{O}_{3}$ & 14.5 & $6-39$ & No \\
\hline 1,2,4-Butanetriol & $\mathrm{C}_{4} \mathrm{H}_{10} \mathrm{O}_{3}$ & 32.2 & $35-50$ & $Y_{e s}^{\prime}$ \\
\hline \multicolumn{5}{|l|}{ Deoxysugar acids } \\
\hline 3,4-Dihydroxybutyric acidi,j & $\mathrm{C}_{4} \mathrm{H}_{8} \mathrm{O}_{4}$ & 16.5 & - & $Y_{e s}^{n}$ \\
\hline \multicolumn{5}{|l|}{ Sugars } \\
\hline Ribose & $\mathrm{C}_{5} \mathrm{H}_{10} \mathrm{O}_{5}$ & $64.7,65.0$ & $237-2467$ & No \\
\hline
\end{tabular}

$\mathrm{K}$, such reactive species have very limited mobility, and radical recombination takes place between neighboring species, both at low temperature and during warm-up, resulting in the formation of a wide variety of new species which are not necessarily the most thermodynamically stable products. However, UV photons can also break newly formed species into smaller fragments, so that the pathway towards the formation of a given product is the result of multiple recombination and destruction reactions. Consequently, the number of photons required to form larger molecules is typically larger than the number of chemical steps required to go from reactants to products.

Under these conditions, all products identified in the final residues likely form via several distinct pathways rather than only one. Such processes have been studied in more detail for the formation of amino acids from the UV irradiation of ices under similar experimental conditions ${ }^{31}$. In addition, we would note that some photoproducts may be formed during the warm-up stage, after UV photolysis, from species formed at low temperature and trapped in the ices until the temperature is high enough for them to be mobile and react. During the warm-up process, smaller, higher-volatility compounds may either sublime away or stay trapped in the residues, resulting in a loss of some of these photoproducts. Therefore, due to the stochastic nature of the processes taking place in UV irradiation experiments at low temperature and the subsequent warm-up to room temperature, the final abundances of the photoproducts recovered in the residues (at room temperature) can vary significantly from one sample to another (Table 1), even when experiments are performed under very similar experimental conditions.

Sugar derivatives have been shown to form abiotically via formose-type reactions from the oligomerization of formaldehyde in an aqueous solution in the presence of a basic catalyst and small amounts of one or more initiators such as glycolaldehyde, glyceraldehyde, dihydroxyacetone, or any larger sugar ${ }^{32,33}$. Formose-type reactions may also, in some cases, be initiated by UV light without any catalyst or initiator ${ }^{34}$. This mechanism was proposed to form the sugars (including ribose) and other sugar derivatives produced from the UV irradiation of one 

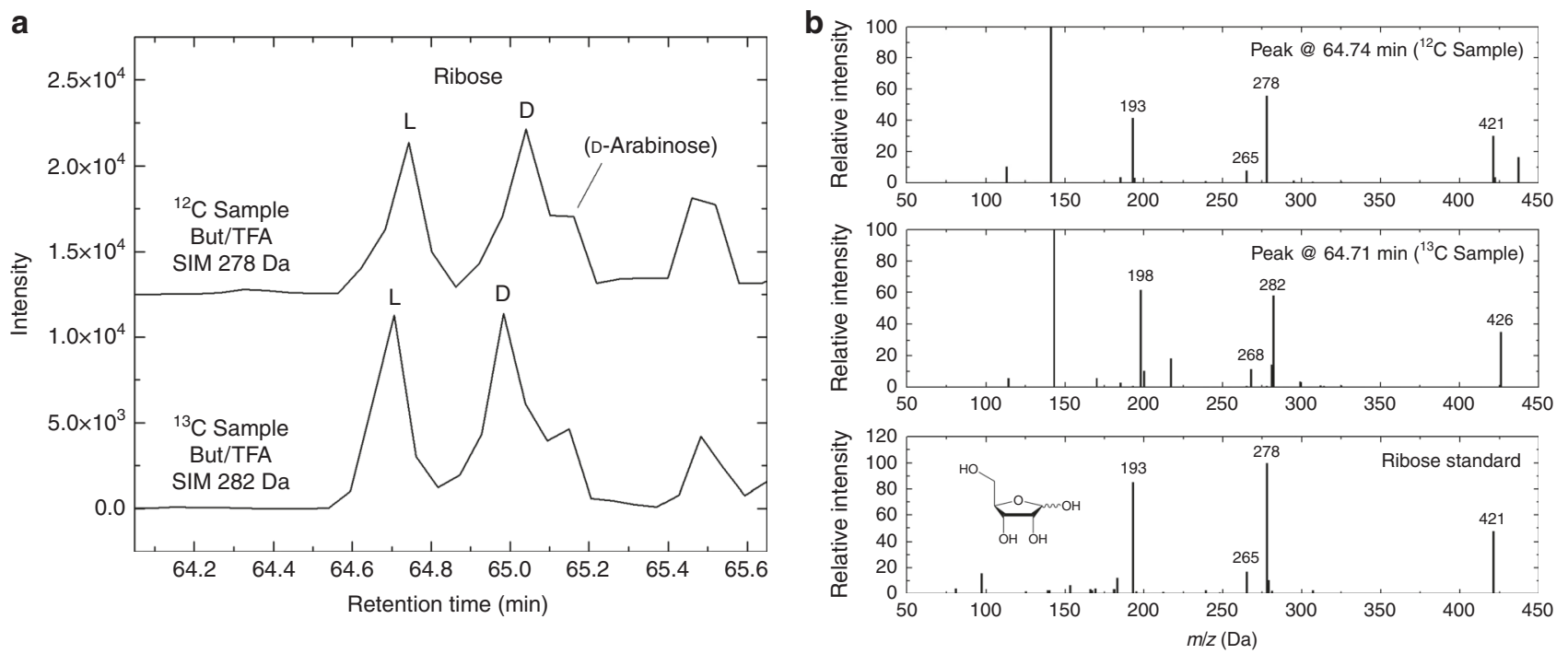

Fig. 3 Identification of ribose in ice photolysis residues. a $\mathrm{SIM}$ chromatograms of residues produced from the $\mathrm{UV}$ irradiation of $\mathrm{H}_{2} \mathrm{O}: \mathrm{CH}_{3} \mathrm{OH}(2: 1)\left({ }^{12} \mathrm{C}\right.$ sample, $m / z=278 \mathrm{Da})$ and $\mathrm{H}_{2} \mathrm{O}:{ }^{13} \mathrm{CH}_{3} \mathrm{OH}(2: 1)\left({ }^{13} \mathrm{C}\right.$ sample, $\left.282 \mathrm{Da}\right)$ ice mixtures after derivatization with $(+)$-2-butanol/TFAA. Intensities are offset for clarity. $\mathbf{b}$ From top to bottom, mass spectra of the peaks assigned to L-ribose in the regular residue, the ${ }^{13} \mathrm{C}$-labeled residue, and a standard of ribose. The molecular structure of ribose is shown without derivatization. Assignments of the fragments in the mass spectra can be found in Supplementary Table 1

\section{Table 2 Ratios between the abundances of 2-deoxyribose and ribose in the residues}

\begin{tabular}{lll} 
Samples & $\begin{array}{l}\text { Deoxyribose/ribose } \\
\text { ratio }(\mathbf{D}+\mathbf{L})^{\mathbf{a}}\end{array}$ & $\begin{array}{l}\text { Deoxyribose/ribose } \\
\text { ratio }(\mathbf{L} \text { only })^{\mathbf{a}}\end{array}$ \\
\hline Regular residues & $0.15-3.33$ & $0.23-4.45$ \\
${ }^{13}$ C-residues & $0.23-0.24$ & $0.31-0.33$ \\
\hline
\end{tabular}

aRatios were calculated from the total abundances of either both $D+L$ enantiomers (after subtracting the contribution from contaminant ${ }^{12} \mathrm{C}$-2-deoxy-D-ribose, see Supplementary Fig. 5) or L enantiomers only.

$\mathrm{H}_{2} \mathrm{O}:{ }^{13} \mathrm{CH}_{3} \mathrm{OH}: \mathrm{NH}_{3}$ ice mixture in an independent study ${ }^{28}$. However, no experimental proof of such a mechanism was provided in that study, and the experimental conditions of formosetype reactions are quite different from those in ice irradiations. Moreover, although formaldehyde is one of the major photoproducts of methanol when subjected to UV irradiation ${ }^{35}$, its formation requires several reaction steps from the starting methanol, so it forms together with a number of other, competing methanol photoproducts. However, once formed, formaldehyde may undergo a photo-induced oligomerization similar to a formose-type reaction process, leading to the formation of sugars and sugar derivatives. In addition, a formose-type mechanism is expected to yield sugars as the majority products, including branched compounds, but no deoxysugar derivatives ${ }^{32,33}$. The presence of several deoxysugar derivatives in our residues, including 2-deoxyribose with abundances sometimes higher than ribose, therefore indicates that other competing mechanisms are also involved in the formation of the identified photoproducts.

To the best of our knowledge, only two other abiotic synthesis of 2-deoxyribose have previously been reported in the literature, although neither describes a detailed formation mechanism. The first one involves the reaction between acetaldehyde $\left(\mathrm{C}_{2} \mathrm{H}_{4} \mathrm{O}\right)$, glyceraldehyde $\left(\mathrm{C}_{3} \mathrm{H}_{6} \mathrm{O}_{3}\right)$, and calcium oxide $(\mathrm{CaO})$ at $50^{\circ} \mathrm{C}$ in an aqueous solution, which leads to a production yield of $3 \%$ for 2 deoxyribose $e^{36}$. The use of formaldehyde $\left(\mathrm{H}_{2} \mathrm{CO}\right)$ instead of glyceraldehyde led to a smaller yield. The second reported abiotic synthesis of 2-deoxyribose describes the photo-induced deoxygenation of the $5 \mathrm{C}$ sugars ribose and/or arabinose in solution, when mixed with a solution of $\mathrm{H}_{2} \mathrm{O} / \mathrm{D}_{2} \mathrm{O}, \mathrm{NaH}_{2} \mathrm{PO}_{4} \cdot 2 \mathrm{H}_{2} \mathrm{O}$, $\mathrm{KSCN}$, and $\mathrm{NaSH} \bullet x \mathrm{H}_{2} \mathrm{O}$ at $37^{\circ} \mathrm{C}, \mathrm{pH} 7$, and when subjected to the UV light emitted by $\mathrm{Hg}$ bulbs $(\lambda=254 \mathrm{~nm})^{37}$. After $6 \mathrm{~h}$ of irradiation, it was found that more than half of the starting ribose/arabinose had been converted into photoproducts, among which 2 -deoxyribose was identified using ${ }^{1} \mathrm{H}$-NMR analysis ${ }^{37}$.

The ratios of the abundance of 2-deoxyribose to that of ribose in our residues span a wide range, i.e., $0.15-3.33$ for $\mathrm{D}+\mathrm{L}$ enantiomers and 0.23-4.45 for L enantiomers only (Table 2). While a more detailed study is necessary to formally determine the mechanism(s) involved in the formation of deoxysugar derivatives under our experimental conditions, these ratios do not point to any particular mechanism for the formation of 2-deoxyribose. Possibilities for 2-deoxyribose formation therefore include a bottom-to-top mechanism involving smaller intermediates than $5 \mathrm{C}$ sugar derivatives (such as described in ref. ${ }^{36}$ ), a photo-induced deoxygenation of ribose and/or arabinose previously made from the ice irradiation (such as described in ref. ${ }^{37}$ ), or a combination of both pathways, as would be expected from the stochastic nature of the processes involved in the formation of these compounds. In any case, our results do not support formation mechanisms involving only formose-type reactions ${ }^{32,33}$.

Deoxysugar derivatives were also found to be present in carbonaceous chondrites such as Murchison in the form of $4 \mathrm{C}-6 \mathrm{C}$ deoxysugar acids ${ }^{4,5}$. The wide variety of deoxysugar acids present in detectable quantities in the Murchison and Murray meteorites mirrors the variety of canonical sugar acids found in the same meteorites. Indeed, sugar acids were found to be the second most abundant family of polyols present in meteorites after sugar alcohols, while only one sugar, dihydroxyacetone, a ketose sugar, was detected ${ }^{4}$. An analysis of Murchison and Graves Nunataks (GRA) 06100 meteorite samples for this study shows that small 

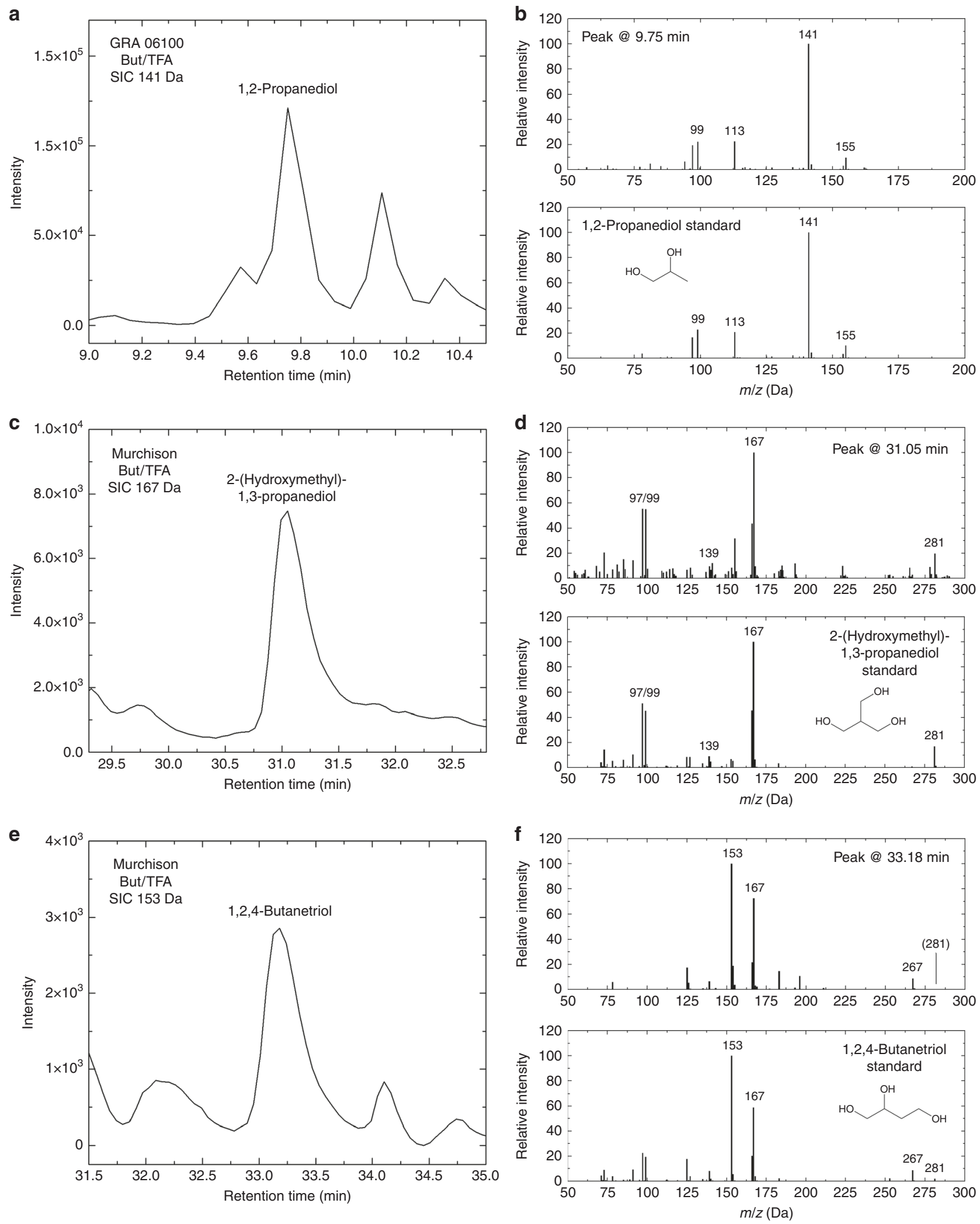

Fig. 4 Identification of three deoxysugar alcohols in meteorites. a Single-ion chromatogram (SIC) of a sample from GRA $06100(\mathrm{~m} / z=141 \mathrm{Da})$ derivatized with (+)-2-butanol/TFAA. b Mass spectrum of the peak assigned to 1,2-propanediol, compared with the mass spectrum of a standard of 1,2-propanediol. c SIC of a sample from Murchison (167 Da) derivatized with (+)-2-butanol/TFAA. d Mass spectrum of the peak assigned to 2-(hydroxymethyl)-1,3propanediol, compared with the mass spectrum of a standard of 2-(hydroxymethyl)-1,3-propanediol. e SIC of the same Murchison sample (153 Da). $\mathbf{f}$ Mass spectrum of the peak assigned to 1,2,4-butanetriol, compared with the mass spectrum of a standard of 1,2,4-butanetriol. Deoxysugar alcohols only accept TFAA derivatization under the present conditions, i.e., only O-TFA bonds are formed. Molecular structures are shown without derivatization. Assignments of the fragments in the mass spectra can be found in Supplementary Table 1 
deoxysugar alcohols are also present in meteorites (Fig. 4): 1,2propanediol (3C) was found in Murchison and GRA 06100, but not its isomer 1,3-propanediol, while 2-(hydroxymethyl)-1,3propanediol (4C, branched) and 1,2,4-butanetriol (4C) were both found in Murchison. The presence of a small compound such as 1,2-propanediol in GRA 06100 is surprising, as the parent body of this meteorite is believed to have experienced temperatures as high as $600{ }^{\circ} \mathrm{C}^{38}$. However, the pyrolysis $\left(>500^{\circ} \mathrm{C}\right)$ of 1,2 -propanediol showed that this compound is stable at very high temperatures $^{39}$, which supports its presence in GRA 06100. Larger deoxysugars such as 2-deoxyribose and 2-deoxyglucose were also searched for in these meteorites, but their presence could not be unambiguously confirmed (larger sample sizes might be needed). Among all these compounds, only 1,2-propanediol and 1,2,4butanetriol were also found in our residues (Table 1).

This observation does not rule out a formation of sugars and deoxysugars via ice photochemistry in cold astrophysical environments along with their alcohol and acid derivatives, although it seems to indicate that sugars and deoxysugars may not be as stable as their alcohol and acid counterparts in the physical and chemical environments they experience between their formation and their incorporation into meteorite parent bodies, i.e., asteroids and comets. The absence of sugars-except one-and lack of definitive detection of deoxysugars in the meteorites analyzed so far may also be due to their very low abundances and/or the result of their reduction or oxidation into the corresponding alcohol and acid derivatives, respectively, in the astrophysical environments where they formed or after aqueous alteration in asteroids and comets. Future analyses of larger meteoritic samples might be more conclusive in the hunt for compounds such as deoxyribose, in particular because deoxyribose is more stable than ribose. In any case, it indicates that the sugars and deoxysugars essential to terrestrial life may have been delivered to the primitive Earth predominantly in the form of their alcohol and acid derivatives rather than in their aldose/ketose form.

The efficient production of sugar derivatives ${ }^{27,28}$ and deoxysugar derivatives (this work) from the UV irradiation of astrophysical ice analogs supports scenarios in which ice photochemistry plays an important role in the formation of the organics that are detected in carbonaceous meteorites. In particular, the presence of both sugar and deoxysugar derivatives in laboratory residues and meteorites compounds favors ice photochemistry over a formose-type reaction mechanism for their formation, as deoxysugar derivatives have not been reported as products of the formose reaction ${ }^{32,33}$. However, the formation mechanism and meteoritic distribution of these compounds need to be studied in more detail.

Organic compounds of important astrobiological interest that have been found in primitive meteorites, and which include amino acids ${ }^{6,7}$, nucleobases ${ }^{8,9}$, amphiphilic compounds ${ }^{10,11}$, as well as sugar and deoxysugar derivatives ${ }^{4,5}$, were delivered to the primitive Earth via asteroids and comets ${ }^{12,13}$. Though terrestrial processes must also have contributed to the emergence of life on our planet over 3.8 billion years ago ${ }^{40}$, those meteoritic organics were available and may have played a role in the first biological processes. In the case of deoxysugar derivatives, larger (and different) meteorite samples may be more definitive as to their presence in extraterrestrial environments. The formation of complex organics in astrophysical environments and the delivery of compounds of biological importance to telluric planets are believed to be universal events that may have occurred elsewhere in the Universe.

\section{Methods}

Irradiation of ices at low temperature. Gas mixtures were prepared in a glass line (background pressure: $\sim 10^{-6}$ mbar) by mixing the vapors of $\mathrm{H}_{2} \mathrm{O}$ (liquid; purified to $18.2 \mathrm{M} \Omega \mathrm{cm}$ by a Millipore Direct-Q UV 3 device) and either $\mathrm{CH}_{3} \mathrm{OH}$ (liquid; Aldrich, HPLC grade, $\geq 99.9 \%$ purity) or ${ }^{13} \mathrm{CH}_{3} \mathrm{OH}$ (liquid; Cambridge Isotope Laboratories, Inc., $99.9 \%{ }^{13} \mathrm{C}$ ) in a glass bulb (volume: $2.09 \mathrm{~L}$ ). All liquids were freeze-pump-thawed at least three times prior to mixing of their sublimation gases, in order to remove excess dissolved gases. Ratios between mixture components were determined by their partial pressure $( \pm 0.05$ mbar $) . \mathrm{H}_{2} \mathrm{O}: \mathrm{CH}_{3} \mathrm{OH}$ and $\mathrm{H}_{2} \mathrm{O}:{ }^{13} \mathrm{CH}_{3} \mathrm{OH}$ gas mixtures in relative proportion 2:1 were prepared for this work, for total pressures of $\sim 27$ mbar in each bulb.

These gas mixtures were injected into a vacuum cryogenic chamber evacuated to a few $10^{-8}$ mbar, and deposited onto a piece of aluminum (Al) foil (prebaked to $500{ }^{\circ} \mathrm{C}$ ), used as a substrate and attached to a cold finger cooled to $12 \mathrm{~K}$ by a closedcycle helium cryocooler. Deposited mixtures formed amorphous ice films which were simultaneously exposed to UV irradiation for 17-19 h. The UV source used was a microwave-powered $\mathrm{H}_{2}$-discharge UV lamp (Opthos; $\mathrm{H}_{2}$ pressure: $0.1 \mathrm{mbar}$ ) which emits UV photons at $121.6 \mathrm{~nm}$ (Lyman $\alpha$ ) and a continuum centered around $160 \mathrm{~nm}^{41}$, with a flux of $\sim 10^{15}$ photons $\mathrm{cm}^{-2} \mathrm{~s}^{-1}$ (estimate) ${ }^{42}$. Such a light source simulates the UV radiation field in the dense ISM and around protostars ${ }^{43-45}$. In this work, the UV doses received by each sample ranged from 0.35 to 0.39 photon molecule ${ }^{-1}$. Assuming a photon flux of $8 \times 10^{7}$ photons $\mathrm{cm}^{-2} \mathrm{~s}^{-1}$ for photons with energies higher than $6 \mathrm{eV}$ in the diffuse ISM ${ }^{46}$, and fluxes at least 3 orders of magnitude lower in dense interstellar clouds ${ }^{47,48}$, our experiments correspond to a UV irradiation of ices of about $5 \times 10^{4} \mathrm{yr}$ in diffuse media, and $>5 \times 10^{7} \mathrm{yr}$ in denser media. Note that ices are expected to be present mostly in cold, dense molecular clouds, so that the UV dose received by ices in one of our experiments is relevant to the dose ice-coated grains receive during the whole lifetime of a molecular cloud. In addition, such ice-coated grains are expected to experience UV doses up to 100 times higher in the solar nebula ${ }^{49}$, so that one experiment would correspond to a full cycle during which a grain travels out of and back to the protosolar disc midplane. After simultaneous deposition and irradiation, samples were warmed under static vacuum to room temperature at about $0.75 \mathrm{~K} \mathrm{~min}^{-1}$, at which time each residue covering the substrate was taken with $200 \mu \mathrm{L}$ of $\mathrm{H}_{2} \mathrm{O}$ and transferred into a clean, prebaked $\left(500^{\circ} \mathrm{C}\right)$ vial for further analysis.

Analysis of laboratory residues at room temperature. Each $\mathrm{H}_{2} \mathrm{O}$-dissolved residue was divided into smaller aliquots to be analyzed with three different GCMS methods. Before any derivatization, each aliquot was dried in a desiccator under vacuum for $1-2 \mathrm{~h}$. The three derivatizations methods used in this work are: (+)-butanol/TFAA (identification and separation of enantiomers), BSTFA (identification of sugar derivatives containing 3 or more derivatizable groups), and MTBSTFA (identification of smaller deoxysugar derivatives that contain only two $\mathrm{OH}$ groups) derivatizations. Each derivatization method is described in detail in the Supplementary Methods section.

Sugar derivatives in residues were identified by comparison of both their retention times and mass spectra with commercial standards. These standards were purchased from Sigma-Aldrich, unless otherwise stated, and include: (1) deoxysugars: 2-deoxy-D-ribose $\left(\mathrm{C}_{5} \mathrm{H}_{10} \mathrm{O}_{4} ; 97 \%\right)$, 2-deoxy-L-ribose $\left(\mathrm{C}_{5} \mathrm{H}_{10} \mathrm{O}_{4}\right.$; $97 \%)$, 2-deoxy-D-galactose $\left(\mathrm{C}_{6} \mathrm{H}_{12} \mathrm{O}_{5} ; 98 \%\right)$, and 2-deoxy-D-glucose $\left(\mathrm{C}_{6} \mathrm{H}_{12} \mathrm{O}_{5}\right.$; $99 \%)$; (2) deoxysugar alcohols: 1,2-propanediol $\left(\mathrm{C}_{3} \mathrm{H}_{8} \mathrm{O}_{2}\right.$; Alfa Aesar, $\left.>98 \%\right), 1,3$ propanediol $\left(\mathrm{C}_{3} \mathrm{H}_{8} \mathrm{O}_{2}\right.$; Tokyo Chemical Industry Co., $\left.>98.0 \%\right)$, 2-methyl-1,3propanediol $\left(\mathrm{C}_{4} \mathrm{H}_{10} \mathrm{O}_{2}\right.$; Tokyo Chemical Industry Co., >98.0\%), 1,2,3-butanetriol $\left(\mathrm{C}_{4} \mathrm{H}_{10} \mathrm{O}_{3}\right.$; Aldrich $\left.{ }^{\mathrm{CPR}}\right),( \pm)-1,2,4$-butanetriol $\left(\mathrm{C}_{4} \mathrm{H}_{10} \mathrm{O}_{3} ; 95 \%\right)$, and 2-

(hydroxymethyl)-1,3-propanediol $\left(\mathrm{C}_{4} \mathrm{H}_{10} \mathrm{O}_{3} ; 97 \%\right)$; and (3) deoxysugar acids: the four 2,3-dihydroxybutyric acid isomers $\left(2 R, 3 R ; 2 S, 3 S ; 2 R, 3 S\right.$; and $2 S, 3 R ; \mathrm{C}_{4} \mathrm{H}_{8} \mathrm{O}_{4}$; sodium salts, 97\%).

Control experiments. In addition to the regular experiments of UV irradiation of ices, three control samples were prepared: (1) a piece of $\mathrm{Al}$ foil with no deposited ices that was exposed to UV irradiation, (2) a pure $\mathrm{H}_{2} \mathrm{O}$ ice (no methanol) deposited and exposed to UV irradiation, and (3) an $\mathrm{H}_{2} \mathrm{O}^{13} \mathrm{CH}_{3} \mathrm{OH}(2: 1)$ ice mixture deposited but not subjected to UV irradiation. These control experiments were carried out and analyzed with the $(+)$-2-butanol/TFAA method following the same procedure as for all other experiments.

Analysis of meteorite samples. The Murchison meteorite (CM2 chondrite) sample was obtained from the Center for Meteorite Studies, Arizona State University, Tempe, AZ. The GRA 06100 meteorite (CR2) sample was obtained from the Antarctic Meteorite Collection at NASA Johnson Space Center, Houston, TX. The samples of both meteorites were extracted in water, and the organic compounds were fractionated following procedures identical to those described previously ${ }^{50}$. Fractions containing neutral compounds, sugar alcohols, etc., and weak 
acids were derivatized for GC-MS analysis as described above. The amounts of Murchison and GRA 06100 meteorites analyzed correspond to 66 and $50 \mathrm{mg}$, respectively.

\section{Data availability}

Data from this manuscript will be made available on the NASA PubMed Central repository (https://www.nasa.gov/open/researchaccess/pubspace). This includes raw data as well as figures in the form of image files for both the main manuscript and the Supplementary Information. Alternatively, raw data and figure image files are available on request from the corresponding author M.N.

Received: 30 May 2018 Accepted: 14 November 2018

Published online: 18 December 2018

\section{References}

1. Stern, R. \& Jedrzejas, M. J. Carbohydrate polymers at the center of life's origins: The importance of molecular processivity. Chem. Rev. 108, 5061-5085 (2008).

2. Nelson, D. L. \& Cox, M. M. Principles of Biochemistry 6th edn (W. H. Freeman and Company, New York, NY, 2012)

3. Vollhardt, K. P. C. Organic Chemistry 1st edn (W. H. Freeman and Company, New York, NY, 1987).

4. Cooper, G. et al. Carbonaceous meteorites as a source of sugar-related organic compounds for the early Earth. Nature 414, 879-883 (2001).

5. Cooper, G. \& Rios, A. C. Enantiomer excesses of rare and common sugar derivatives in carbonaceous meteorites. Proc. Natl Acad. Sci. USA 113, E3322-E3331 (2016)

6. Martins, Z. \& Sephton, M. in Amino Acids, Peptides and Proteins in Organic Chemistry: Origins and Synthesis of Amino Acids Vol. 1 (ed. Hughes, A. B.) 3-42 (Wiley VCH, Weinheim, 2009).

7. Martins, Z., Modica, P., Zanda, B. \& Le Sergeant d'Hendecourt, L. The amino acid and hydrocarbon contents of the Paris meteorite: insights into the most primitive CM chondrite. Meteorit. Planet. Sci. 50, 926-943 (2015).

8. Martins, Z. et al. Extraterrestrial nucleobases in the Murchison meteorite. Earth. Planet. Sci. Lett. 270, 130-136 (2008).

9. Callahan, M. P. et al. Carbonaceous meteorites contain a wide range of extraterrestrial nucleobases. Proc. Natl Acad. Sci. USA 108, 13995-13998 (2011).

10. Deamer, D. W. Boundary structures are formed by organic components of the Murchison carbonaceous chondrite. Nature 317, 792-794 (1985).

11. Deamer, D. W. \& Pashley, R. M. Amphiphilic components of the Murchison carbonaceous chondrite: Surface properties and membrane formation. Orig. Life. Evol. Biosph. 19, 21-38 (1989).

12. Oró, J. Comets and the formation of biochemical compounds on the primitive Earth. Nature 190, 389-390 (1961).

13. Chyba, C. \& Sagan, C. Endogenous production, exogenous delivery and impact-shock synthesis of organic molecules: an inventory for the origins of life. Nature 355, 125-132 (1992).

14. Bernstein, M. P. et al. The formation of racemic amino acids by ultraviolet photolysis of interstellar ice analogues. Nature 416, 401-403 (2002).

15. Muñoz Caro, G. M. et al. Amino acids from ultraviolet irradiation of interstellar ice analogues. Nature 416, 403-406 (2002).

16. Nuevo, M., Auger, G., Blanot, D. \& d'Hendecourt, L. A detailed study of the amino acids produced from the vacuum UV irradiation of interstellar ice analogs. Orig. Life. Evol. Biosph. 38, 37-56 (2008).

17. Nuevo, M., Materese, C. K. \& Sandford, S. A. The photochemistry of pyrimidine in realistic astrophysical ices and the production of nucleobases. Astrophys. J. 793, 125 (2014).

18. Materese, C. K. et al. The photochemistry of purine in ice analogs relevant to dense interstellar clouds. Astrophys. J. 864, 44 (2018).

19. Bernstein, M. P. et al. UV Irradiation of polycyclic aromatic hydrocarbons in ices: production of alcohols, quinones, and ethers. Science 283, 1135-1138 (1999).

20. Bernstein, M. P. et al. Side group addition to the PAH coronene by UV photolysis in cosmic ice analogs. Astrophys. J. 576, 1115-1120 (2002)

21. Dworkin, J. P., Deamer, D. W., Sandford, S. A. \& Allamandola, L. J. Selfassembling amphiphilic molecules: synthesis in simulated interstellar/ precometary ices. Proc. Natl Acad. Sci. USA 98, 815-819 (2001).

22. Nuevo, M. et al. Urea, glycolic acid, and glycerol in an organic residue produced by ultraviolet irradiation of interstellar/pre-cometary ice analogs. Astrobiology 10, 245-256 (2010).
23. de Marcellus, P. et al. Prebiotic significance of extraterrestrial ice photochemistry: detection of hydantoin in organic residues. Astrobiology 11, 847-854 (2011)

24. de Marcellus, P. et al. Aldehydes and sugars from evolved precometary ice analogs: Importance of ices in astrochemical and prebiotic evolution. Proc. Natl Acad. Sci. USA 112, 965-970 (2015).

25. Henderson, B. L. \& Gudipati, M. S. Direct detection of complex organic products in ultraviolet (Lya) and electron-irradiated astrophysical and cometary ice analogs using two-step laser ablation and ionization mass spectrometry. Astrophys. J. 800, 66 (2015).

26. Maity, S., Kaiser, R. I. \& Jones, B. M. Formation of complex organic molecules in methanol and methanol-carbon monoxide ices exposed to ionizing radiation-a combined FTIR and reflectron time-of-flight mass spectrometry study. Phys. Chem. Chem. Phys. 17, 3081-3114 (2015).

27. Nuevo, M., Sandford, S. A., Materese, C. K. \& Cooper, G. W. Search for sugars and related compounds in residues produced from the UV irradiation of astrophysical ice analogs. In Astrobiology Science Conference, Abstract No. 7132 (Lunar and Planetary Institute, 2015).

28. Meinert, C. et al. Ribose and related sugars from ultraviolet irradiation of interstellar ice analogs. Science 352, 208-212 (2016)

29. Gibb, E. L., Whittet, D. C. B., Boogert, A. C. A. \& Tielens, A. G. G. M. Interstellar ice: the infrared space observatory legacy. Astrophys. J. Suppl. Ser. 151, 35-73 (2004).

30. Dartois, E. The ice survey opportunity of ISO. Space Sci. Rev. 119, 293-310 (2005).

31. Elsila, J. E. et al. Mechanisms of amino acid formation in interstellar ice analogs. Astrophys. J. 660, 911-918 (2007)

32. Butlerow, A. Bildung einer zuckerartigen Substanz durch Synthese. Justus Liebigs Ann. Chem. 120, 295-298 (1861).

33. Breslow, R. On the mechanism of the formose reaction. Tetrahedron Lett. 21, 22-26 (1959).

34. Snytnikova, O. A. et al. Study of the photoinduced formose reaction by flash and stationary photolysis. Mendeleev Commun. 16, 9-11 (2006).

35. Abou Mrad, N., Duvernay, F., Chiavassa, T. \& Danger, G. Methanol ice VUV photoprocessing: GC-MS analysis of volatile organic compounds. Mon. Not. R. Astron. Soc. 458, 1234-1241 (2016).

36. Oró, J. \& Cox, A. C. Non-enzymatic synthesis of 2-deoxyribose. Fed. Proc. Carbohydr. 21, 80 (1962)

37. Ritson, D. J. \& Sutherland, J. D. Conversion of biosynthetic precursors of RNA to those of DNA by photoredox chemistry. J. Mol. Evol. 78, 245-250 (2014).

38. Abreu, N. M. \& Bullock, E. S. Opaque assemblages in CR2 Graves Nunataks (GRA) 06100 as indicators of shock-driven hydrothermal alteration in the CR chondrite parent body. Meteorit. Planet. Sci. 48, 2406-2429 (2013).

39. Laino, T. et al. Mechanisms of propylene glycol and triacetin pyrolysis. J. Phys. Chem. A 116, 4602-4609 (2012).

40. Dodd, M. S. et al. Evidence for early life in Earth's oldest hydrothermal vent precipitates. Nature 543, 60-64 (2017).

41. Chen, Y.-J. et al. Vacuum ultraviolet emission spectrum measurement of a microwave-discharge hydrogen-flow lamp in several configurations: application to photodesorption of CO ice. Astrophys. J. 781, 15 (2014).

42. Warnek, P. A microwave-powered hydrogen lamp for vacuum ultraviolet photochemical research. Appl. Opt. 1, 721-726 (1962).

43. d'Hendecourt, L. B., Allamandola, L. J., Grim, R. J. A. \& Greenberg, J. M. Time-dependent chemistry in dense molecular clouds. II. Ultraviolet photoprocessing and infrared spectroscopy of grain mantles. Astron. Astrophys. 158, 119-134 (1986).

44. Allamandola, L. J., Sandford, S. A. \& Valero, G. J. Photochemical and thermal evolution of interstellar/precometary ice analogs. Icarus 76, 225-252 (1988).

45. Bernstein, M. P. et al. Organic compounds produced by photolysis of realistic interstellar and cometary ice analogs containing methanol. Astrophys. J. 454, 327-344 (1995).

46. Mathis, J. S., Mezger, P. G. \& Panagia, N. Interstellar radiation field and dust temperature in the diffuse interstellar matter and in giant molecular clouds. Astron. Astrophys. 128, 212-229 (1983).

47. Prasad, S. S. \& Tarafdar, S. P. UV radiation field inside dense clouds: its possible existence and chemical implications. Astrophys. J. 267, 603-609 (1983).

48. Shen, C. J., Greenberg, J. M., Schutte, W. A. \& van Dishoeck, E. F. Cosmic ray induced explosive chemical desorption in dense clouds. Astron. Astrophys. 415, 203-215 (2004).

49. Ciesla, F. J. \& Sandford, S. A. Organic synthesis via irradiation and warming of ice grains in the solar nebula. Science 336, 452-454 (2012).

50. Cooper, G. W. \& Cronin, J. R. Linear and cyclic aliphatic carboxamides of the Murchison meteorite: Hydrolyzable derivatives of amino acids and other carboxylic acids. Geochim. Cosmochim. Acta 59, 1003-1015 (1995). 


\section{Acknowledgements}

We thank R.L. Walker (NASA Ames, retired) for technical support and A.C. Rios (NASA Ames) for useful comments on the manuscript. This work was supported by the National Aeronautics and Space Administration through the NASA Exobiology Program and the NASA Astrobiology Institute under Cooperative Agreement Notice NNH13ZDA017C issued through the Science Mission Directorate.

\section{Author contributions}

M.N. prepared the laboratory samples (residues) and performed GC-MS analyses with BSTFA derivatization. G.C. performed GC-MS analysis of the residues with (+)-butanol/ TFAA and MTBSTFA derivatizations. M.N. and G.C. analyzed the data to identify the compounds in the residues. S.A.S. helped for the interpretation of the results and their astrobiological implications. M.N. wrote the paper with inputs from G.C. and S.A.S.

\section{Additional information}

Supplementary Information accompanies this paper at https://doi.org/10.1038/s41467018-07693-x.

Competing interests: The authors declare no competing interests.

Reprints and permission information is available online at http://npg.nature.com/ reprintsandpermissions/
Publisher's note: Springer Nature remains neutral with regard to jurisdictional claims in published maps and institutional affiliations.

cc (i) Open Access This article is licensed under a Creative Commons Attribution 4.0 International License, which permits use, sharing, adaptation, distribution and reproduction in any medium or format, as long as you give appropriate credit to the original author(s) and the source, provide a link to the Creative Commons license, and indicate if changes were made. The images or other third party material in this article are included in the article's Creative Commons license, unless indicated otherwise in a credit line to the material. If material is not included in the article's Creative Commons license and your intended use is not permitted by statutory regulation or exceeds the permitted use, you will need to obtain permission directly from the copyright holder. To view a copy of this license, visit http://creativecommons.org/ licenses/by/4.0/.

This is a U.S. government work and not under copyright protection in the U.S.; foreign copyright protection may apply 2018 